\title{
DAXX promotes ovarian cancer ascites cell proliferation and migration by activating the ERK signaling pathway
}

\author{
Sheng-Bing Liu, Xue-Ping Lin, Ying Xu, Zhong-Fei Shen and Wei-Wei Pan ${ }^{*}$
}

\begin{abstract}
Background: The death-domain-associated protein (DAXX) was originally identified as a protein that binds to the transmembrane death receptor FAS and enhances both FAS-induced and transforming growth factor- $\beta$-dependent apoptosis. In a previous study, we found that nude mice injected with DAXX-overexpressing cells (ES-2-DAXX) accumulated large concentrations of first-generation ascites cells (I ascites cells). The role of DAXX in the development of ascites is unknown. The aim of this study was to analyze the effect of DAXX on proliferation and migration of ascites cells in ovarian cancer in vitro and in vivo.

Methods: Nude mice were housed in cages with a 14:10 h light:dark cycle; water and food were provided ad libitum. ES-2-DAXX cells $(1 \times 106)$ were injected intraperitoneally into athymic nude mice (8-week-old female mice). After 4 weeks, I ascites cells were collected. The I ascites cells were injected intraperitoneally into athymic nude mice (8-week-old female mice). After 4 weeks, II ascites cells were collected and cultured. Ascites cell survival, migration, and colony formation were measured using colony formation and cell growth assays. Immunofluorescent staining revealed the co-localization of DAXX and promyelocytic leukemia protein (PML) in ascites cell nuclei. Western blotting and immunohistochemistry showed that extracellular signal-related kinase (p-ERK) 1/2 and CEBP- $\beta$ were highly expressed in tumor tissues formed by II ascites cells. Through immunoprecipitation, we also found that DAXX can interact with CEBP- $\beta$.

Results: DAXX enhanced ascites cell survival, migration, and colony formation. DAXX and PML nuclear foci dramatically increased in a passage-dependent manner in ascites cells, DAXX promoted the tumor growth of ascites cells in vivo, increased ascites cell proliferation in vivo, and enhanced ascites cell survival and migration by activating the ERK signalling pathway and integrating with CEBP- $\beta$.
\end{abstract}

Conclusions: DAXX can interact with CEBP- $\beta$. DAXX can induce ovarian cancer ascites formation by activating the ERK signal pathway and binding to CEBP- $\beta$.

Keywords: DAXX, Ascites cell, Cell proliferation, Cell migration

\section{Introduction}

Ovarian cancer is the fifth most common cause of death in women, and the second most common gynecological cancer worldwide [1]. Serous ovarian cancer is the most common subtype; most patients present with late-stage tumor and dissemination of tumor implants throughout the peritoneal cavity [2]. Ascites creates a protective environment for ovarian tumor cells that inhibit druginduced apoptosis [3, 4]. Ascites is described as

\footnotetext{
* Correspondence: wwpan@mail.zjxu.edu.cn

College of Medicine, Jiaxing University, Jiaxing 314001, China
}

heterogeneous fluids that display marked differences in their levels of soluble factors; some of these factors can potentially activate an array of signaling pathways [5].

Ascites formation is an important problem in patients with ovarian cancer. The development of ascites is a hallmark symptom of late-stage ovarian cancer, and biologically active factors within the fluid can affect disease progression and interfere with anti-tumor vaccination strategies [6, 7]. The mechanism of ovarian cancer ascites formation is unknown. In a previous study, we found that DAXX-overexpressing cells (ES-2-DAXX) accumulated

(c) The Author(s). 2018 Open Access This article is distributed under the terms of the Creative Commons Attribution 4.0 International License (http://creativecommons.org/licenses/by/4.0/), which permits unrestricted use, distribution, and 
large concentrations of ascites cells [8]. Based on these data, we found that DAXX-overexpression-induced ascites cells had an increased colony number and migration ability in vitro. We further demonstrated that the ERK pathway was activated in DAXX-overexpression-induced ascites cells. We also found that DAXX interacted with CEBP- $\beta$ in DAXX-overexpression-induced ascites cells. Our results indicated that DAXX promotes ovarian cancer ascites cell proliferation by activating the ERK pathway and directly binding to CEBP- $\beta$.

\section{Methods}

\section{Reagents and cell culture}

ES-2 cells (human ovarian cancer cell lines) purchased from the ATCC (Manassas, VA, USA) were cultured in DMEM (Dulbecco's Modified Eagle's Medium) which contains $10 \%$ fetal bovine serum and $1 \%$ penicillin-streptomycin solution (Hyclone, GE Healthcare, Little Chalfont, UK) at $37{ }^{\circ} \mathrm{C}$ in a humidified $5 \%$ $\mathrm{CO}_{2}$ incubator.

\section{Plasmids and Daxx-overexpressing ovarian cancer cell lines}

The plasmid of pLEGFP-Daxx which encode the fulllength $\operatorname{Daxx}$ sequence and HA-CEBP- $\beta$ were kindly provided by Zhejiang University Professor Fan Heng-yu. Overexpressed ES-2-DAXX cells were established using the methods described previously [8].

\section{Ascites cells and xenograft models}

Nude mice were housed in cages with a 14:10 h light:dark cycle; water and food were provided ad libitum. The NIH Guides for the Care and Use of Laboratory Animals were used as all animal protocols. ES-2-DAXX (The abbreviation of ES-2-DAXX cells is ES-DAXX in all figures.) $\left(1 \times 10^{6}\right)$ were injected intraperitoneally into athymic nude mice (8-week-old female mice), ovarian cancer ascites cells in vivo were obtained through the above experiments.After 4 weeks, ascites cells were collected and centrifuged at $157 \mathrm{~g}$ for $10 \mathrm{~min}$. The acellular fractions were cultured in DMEM which contained $10 \%$ fetal bovine serum mediums and $1 \%$ penicillin-streptomycin in a humidified $5 \%$ $\mathrm{CO}_{2}$ incubator at $37{ }^{\circ} \mathrm{C}$. These cells were designated I ascites cells. The I ascites cells $\left(1 \times 10^{6}\right)$ were injected intraperitoneally into athymic nude mice (8-week-old female mice). After 4 weeks, II ascites cells were collected and cultured. Nude mice were injected with the BrdU solution to a concentration of $100 \mathrm{mg} / \mathrm{kg}$. Two hours later, primary tumor, ovaries, and intestinal masses were collected from athymic nude mice, these primary tumor and organs were fixed with $4 \%$ formalin and made into slices (5- $\mu$ m thick), then the slices were stained with HE (hematoxylin and eosin) staining.

\section{Colony formation assay}

Single ascites cell suspensions were prepared and seeded. Colonies were counted after 10 days in $60-\mathrm{mm}$ dishes. The dishes were cultured in triplicate in a $5 \% \mathrm{CO}_{2} \mathrm{hu}$ midified incubator at $37^{\circ} \mathrm{C}$.

\section{Transwell migration assay}

For the transwell migration assay, 24-well plate inserts with $8-\mu \mathrm{m}$ pore filters, the migration was assessed with BioCoat Matrigl (BD Biosciences, San Jose, CA, USA). $5 \times 10^{4}$ cells was added to serum-free medium and suspended in a transwell. Ascites cells stably transfected with DAXX at the upper surface of the transwells were removed after cells were incubated for $24 \mathrm{~h}$ at $37^{\circ} \mathrm{C}$. Migrated cells were stained with $\mathrm{H} \& \mathrm{E}$ staining and rinsed with double distilled water, then the transwells were air-dried. The positive cells were counted by ImagePro Plus 6.0 software.

\section{Cell growth assay}

Cell proliferation was assessed by MTT assay. Ascites cells were cultured and seeded in plates, the cell densities of the 96-well plates was $3 \times 10^{3}$ cells/well. After the cell adhered to the wall, the 96-well plates was added $20 \mu \mathrm{l} /$ well MTT solution ( $5 \mathrm{mg} / \mathrm{ml}$ in PBS) and was put into incubator in $37{ }^{\circ} \mathrm{C}$ for $4 \mathrm{~h}$. Absorbance value was tested using micro-plate reader at $490 \mathrm{~nm}$.

\section{Soft agar colony formation assay}

Cells were cultured using the method of Hamburger and Salmon with modifications. $1.5 \mathrm{ml}$ of $0.5 \%$ agar were prepared in 6-well. Cells were suspended in $1.5 \mathrm{ml}$ of $0.35 \%$ agar containing $1 \times$ cell culture medium and $10 \%$ fetal bovine serum and poured over these underlayers. The final cell concentration in each culture was $0.5 \times 10^{3}$ cells $/ \mathrm{ml}$. Triplicate cultures were used for each experiment. The plates were placed in a $5 \% \mathrm{CO}_{2}$ humidified incubator at $37{ }^{\circ} \mathrm{C}$. Colonies were counted at 2 to 3 weeks after plating using an Omnicon FAS II Image Analysis System.

\section{Immunohistochemistry}

Paraffin-embedded human ovarian tumor tissues were obtained from the Jiaxing Maternity and Child Health Care Hospital, China. The archived human ovarian tumor tissues used in the experiments had the Jiaxing University Institutional Review Board approval. 5- $\mu \mathrm{m}$ sections were made, referring to $\mathrm{ABC}$ kit (Vector Laboratories, Burlingame, CA, USA), sections stained includes the following aspects: deparaffinized, rehydrated, and antigen retrieval, after the sections were incubated in $\mathrm{H}_{2} \mathrm{O}_{2}$ $(0.3 \%)$ for $10 \mathrm{~min}$, the sections were incubated in $10 \%$ goat serum for $30 \mathrm{~min}$. Then the sections stained with affinity-purified anti-BrdU, anti-DAXX (Sigma Aldrich, 
St. Louis, MO, USA), anti-p-AKT, anti-p-ERK (Cell Signaling Technology, Danvers, MA, USA), and antiCEBP- $\beta$ (Santa Cruz Biotechnology, Dallas, TX, USA) antibodies (1:200 dilution), The antibodies were incubated for $1 \mathrm{~h}$. After washing with PBS, the sections were incubated with a secondary antibody for $30 \mathrm{~min}$ and washed again with PBS before incubation with avidin-biotin complex $(A B C)$ solution. The sections were stained through $\mathrm{DAB}$ (diaminobenzidine) (DAB substrate kit, Vector Laboratories) staining.

\section{Immunofluorescence}

Nude mouse tumor tissues were gained to make microtome section, the tissues embedded in OCT compound (Sakura Finetek USA, Torrance, CA, USA) after fixed in 4\% paraformaldehyde, then Leica CM1850 cryomicrotome (Leica Microsystems) was used to slice. Ascites cells of nude mouse were washed with PBS after the cells were seeded on coverslips for $24 \mathrm{~h}$, then ascites cells were fixed and permeabilized, 5\% BSA was used as blocking reagent. The ascites cells were incubated with primary antibodies at room temperature for $1 \mathrm{~h}$. The sections of ascites cells were stained through DAPI.

\section{RNA extraction and real-time RT-PCR analysis}

Total RNA was extracted from cultured cells using Trizol reagent (Invitrogene), according to the manufacturer's instructions. Real-time PCR analysis was performed using TB Green Premix qPCR kit (TaKaRa, Japan) and an Applied 7300 Real-Time PCR System. Relative mRNA levels were determined by normalizing to the endogenous Gapdh mRNA.

Gapdh:5' -gcctggagaaacctgccaagtatg-3'; 5' -

gagtgggagttgctgttgaagtcg- $3^{\prime}$;

$C E B P-\beta: 5^{\prime}$-gacaagcacagcgacgagta- $3^{\prime} ; 5^{\prime}$ -

agctgctccaccttcttctg-3'

Fog2: 5' -tggggacacacagtcagaga-3'; 5' -

cctcagagatggccttcgta-3'

Tff1: 5' -gaaggtcatgtcaagggaggt- $3^{\prime} ; 5^{\prime}$ -

atgagcttgcaccacgttct-3'

\section{Western blotting}

The proteins extracted from ascites cells were separated by SDS-PAGE and transferred to PVDF membranes, then the membranes were incubated with 5\% BSA for $1 \mathrm{~h}$ at room temperature. The membranes were incubated with primary antibodies for $1 \mathrm{~h}$ at room temperature and the horseradish peroxidase-conjugated goat anti - rabbit antibodies were used as second antibodies (Cell Signaling Technology). After incubated for $1 \mathrm{~h}$ at room temperature, the membranes were washed with TBST. Bound antibodies were visualized through ECL Western Blotting chemiluminescence reagent kit
(Amersham, GE Healthcare).The primary antibodies dilution was1:1000, antibodies which were tested included DAXX (Sigma Aldrich), ERK, CEBP- $\beta, \quad p-E R K$ and $\beta$-actin (Cell Signaling Technology).

\section{Immunoprecipitation}

To detect protein-protein interactions, the vector HACEBP- $\beta$ were transfected into ascites cells. After transfection, Ascites cells were lysed $48 \mathrm{~h}$ using NP-40 buffer. The lysates were centrifuged at $13,000 \times g$ for $25 \mathrm{~min}$. By using anti-HA M2 affinity beads (Sigma Aldrich) for $4 \mathrm{~h}$ at $4{ }^{\circ} \mathrm{C}$, immunoprecipitation was performed. The NTEN buffer was boiled in loading buffer $(4 \times$ SDS) after the beads were washed in NTEN buffer, then separated by electrophoresis (SDS-PAGE). The membranes were incubated with antibodies included DAXX, CEBP- $\beta$, and $\beta$-actin after incubated with 5\% BSA.

\section{Statistical analysis}

The in vitro assays results were repeated for three times. The statistical techniques employed for analysis are one-way ANOVA using GraphPad Prism statistical software (GraphPad Prism, La Jolla, CA, USA) and two-tailed T-tests. To consider $p<0.05$ as statistically significant.

\section{Results \\ DAXX enhances ascites cell survive, migration, and colony formation}

To investigate the role of DAXX in ascites cells, we developed first- and second-generation ovarian cancer ascites cells (I ascites cells and II ascites cells) with stable green fluorescent protein (GFP)-DAXX expression. First, we investigated the role of DAXX in ascites cell survive, migration, and colony formation. As shown in Fig. 1a-b, II ascites cells grew faster than the parental GFP-DAXX overexpression cells, as assessed by MTT assays. The role of DAXX on ascites cell migration was also determined. We found that overexpressed DAXX markedly promoted ascites cells migration (Fig. 1c-d). Furthermore, DAXX expression in ascites cells strongly promoted colony formation (Fig. 1e-f). Notably, one important criterion distinguishes malignant cancer cells from "normal" cells is their ability to grow in soft agar. 3D cell cultures are well documented to better mimic the in vivo situation than monolayer cell culture on plastic [9-11]. Then, we compared the cell growth of ES-2-DAXX cells, I ascites cells and II ascites cells under soft agar and anchorage-independent conditions (in cell suspension). We found that II ascites cells showed a significantly stronger growth potential than ES-2-DAXX cells in soft agar and suspension (Fig. 1g-h). These results demonstrate that DAXX promoted ascites cell proliferation and migration in a passage-dependent manner. 

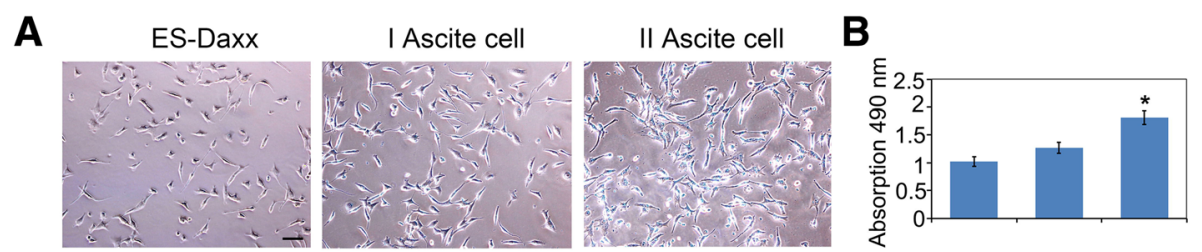

C
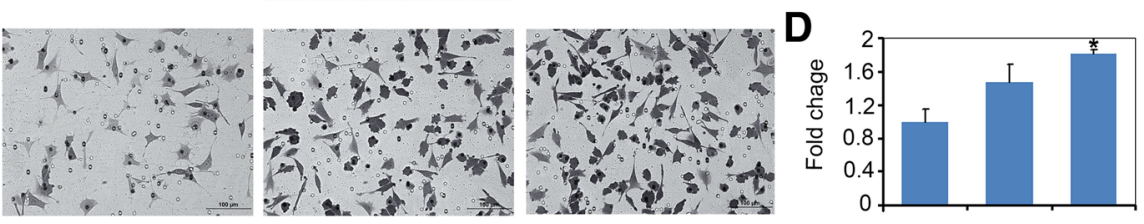

E
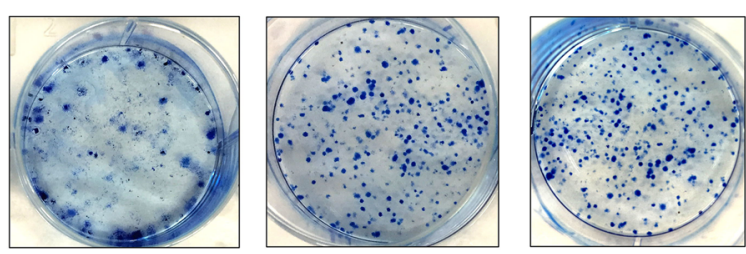

$\mathbf{F}$

G
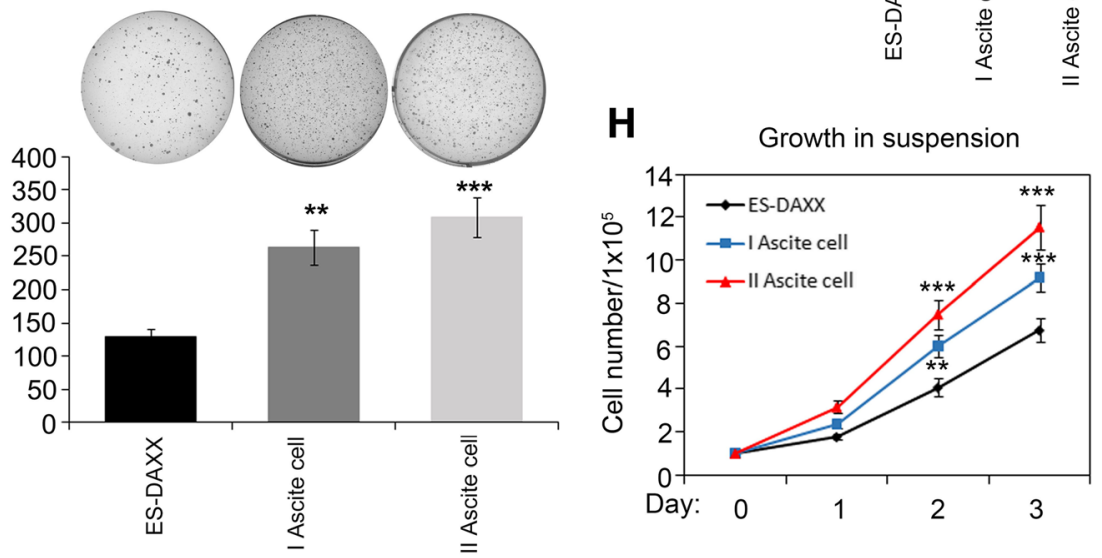

Fig. 1 DAXX enhances ascites cell colony formation and migration. a-b DAXX-induced ascites cell proliferation. Ascites cells were seeded into 96-well plates (3,000 cells/well) overnight, and then assessed by an MTT assay. Scale bar, $50 \mu \mathrm{m}$. c-d Transwell experiment to determine the migration capability of ascites cells and their derivatives (GFP-DAXX-overexpressing ascites cells). Cells were added to transwells and allowed to migrate for $12 \mathrm{~h}$. Cells at the upper surface of the membrane were removed with cotton swabs, and cells on the bottom surface were stained with hematoxylin and eosin. Scale bar, 100 mm. e-f Colony formation assay for the growth of ascites cells with DAXX overexpression. Colony numbers were counted after 10-14 days. ${ }^{*} p<0.05 ;{ }^{* *}, p<0.0001$. g DAXX overexpression promotes anchorage-independent growth of ascite cells in vitro. Soft-agar colony-formation assay was performed and the colonies were stained with crystal violet for quantification. $\mathbf{h}$ DAXX overexpression promoted cell proliferation in suspension (detachment) conditions. Cells $\left(1 \times 10^{5}\right)$ were plated in 6-well culture dishes and cell number was determined with trypan blue staining. Three replicates were included. The error bars represent s.d. ns $(p>0.05) ;{ }^{* * *} p<0.001$. Student's t-test was applied

DAXX and promyelocytic leukemia protein (PML) nuclear foci dramatically increase in a passage-dependent manner in ascites cells

To explore the role of DAXX on ascites cells, we harvested and cultured ascites cells in DMEM medium (Fig. 2a). Western blot examination revealed that the ascites cells were positive for GFP-DAXX (Fig. 2b), which illustrated that ascites cells were derived from the parental ES-Daxx cells. Through immunostaining, we found that DAXX nuclear aggregation significantly increased in a passage-dependent manner (Fig. 2c). In our previous study, we found that DAXX co-localized with PML in ovarian cancer cells and mouse ovarian surface epithelium
(mOSE) [12]. Here, we sought to quantify PML expression in ascites cells through immunofluorescence staining. We found that PML exhibited nuclear location in ascites cells; this distribution was consistent with DAXX in ascites cells nuclei (Fig. 2d-e).

DAXX promotes the tumor growth of ascites cells in vivo We also detected the role of DAXX in promoting the tumorigenic and metastatic capabilities of ascites cells. Female nude mice were injected intraperitoneally with either parental ES-2-DAXX cells or ascites cells. As shown in Fig. 3a-b, the average weight of the abdominal solid tumors formed by II ascites cells was approximately 


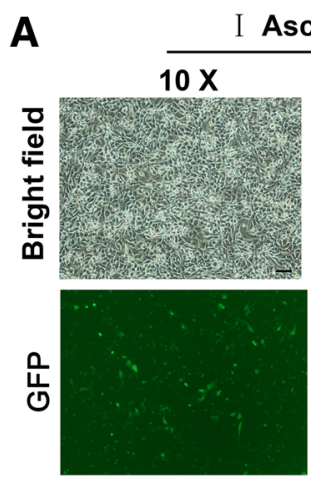

C

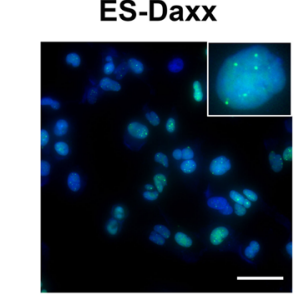

D

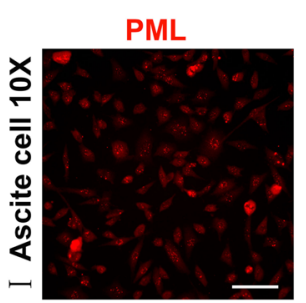

E

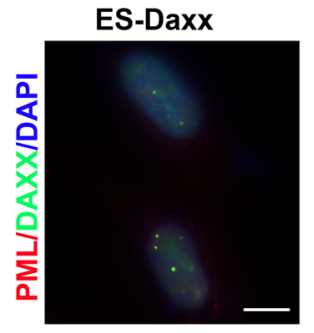

I Ascite cell

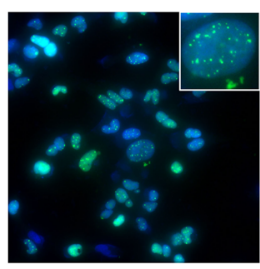

DAXX

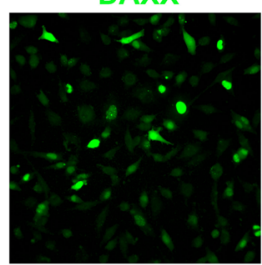

I Ascite cell

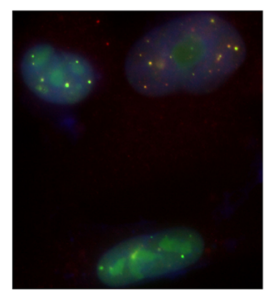

B

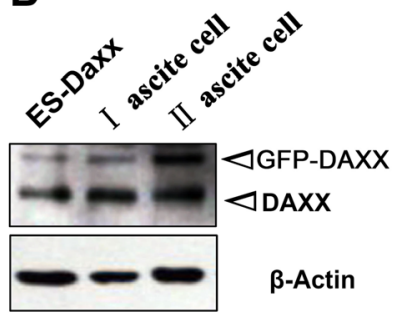

II Ascite cell

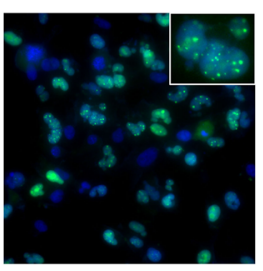

DAPI/merge

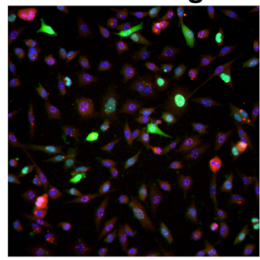

II Ascite cell

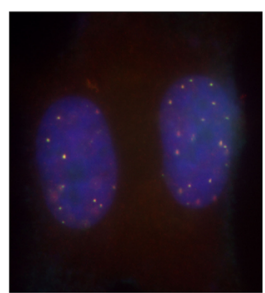

Fig. 2 DAXX and PML nuclear localization in ascites cells. a Ascites cell morphology using brightfield and GFP microscopy (10 x and 20x magnification, respectively). $\mathbf{b}$ Western blot results for DAXX overexpression in ascites cells. c Ascites cells were harvested from nude mice and cultured in vitro. Fluorescence microscopy showing the localization of overexpressed DAXX (green) in ascites cells stably transfected with GFP-DAXX. Nuclei were stained with 4',6-diamidino-2-phenylindole (DAPI; blue). Scale bar, $50 \mu \mathrm{m}$. d Immunofluorescence results for promyelocytic leukemia protein (PML) foci formation in ascites cells. Scale bar, 50 mm. e Immunofluorescence results for PML, DAXX and DAPI in ES-Daxx, I and II ascites cells. Scale bar, $10 \mu \mathrm{m}$

threefold greater than the average weight of the control formed by the parental ES-2-DAXX cells. The ascites formation time decreased in a passage-dependent manner (Fig. 3c). Examination of the peritoneal cavities of mouse that injected II ascites cells showed a significant and dispersed distribution of tumor exposites in the ovary and intestine (Fig. 3d).

\section{DAXX increases ascites cell proliferation in vivo}

To illuminate the role of DAXX on ascites cells proliferation, we observed GFP expression. Fluorescence microscopy showed that the most of the tumor cells were derived from ES-2-DAXX ascites cells (Fig. 4a). Immunohistochemical examinations showed that DAXX and PML were all significantly expressed in ascites cell-derived tumors (Fig. 4b). Next, we measured bromodeoxyuridine (BrdU) levels through immunohistochemical staining. We found that BrdU was present in high concentrations in ascites cell-derived tumors (Fig. 4c). These results showed that DAXX promotes ascites cell proliferation in vivo.

DAXX enhances ascites cell survival and migration by activating the ERK signaling pathway and integrating with CEBP- $\beta$

To understand how DAXX expression promoted ascites cells growth, we measured p-ERK1/2 and p-AKT 


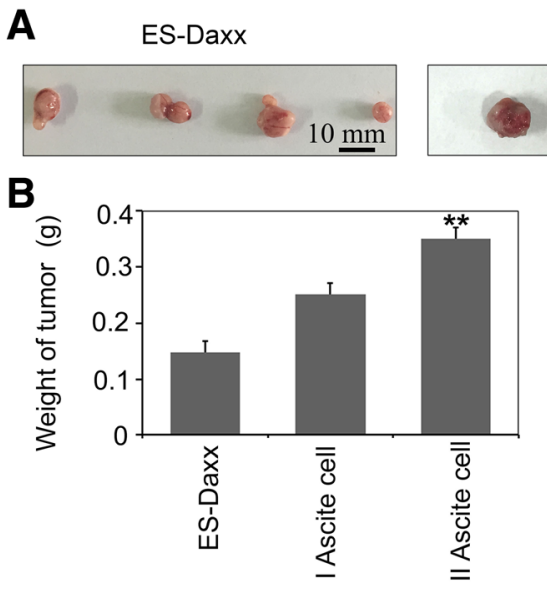

D

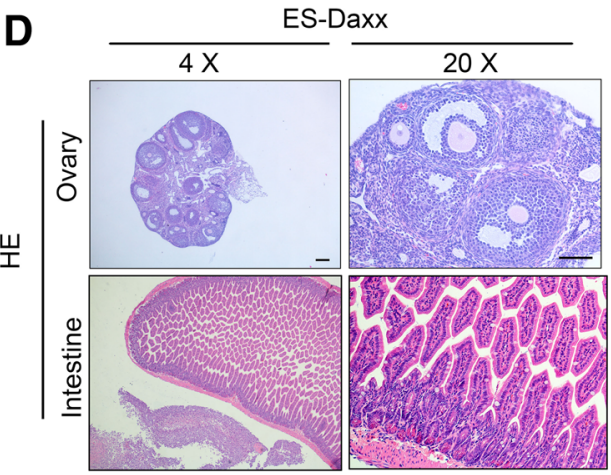

Ascites cell

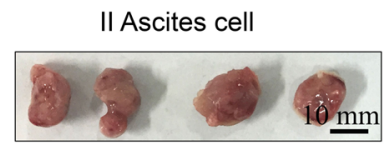

C
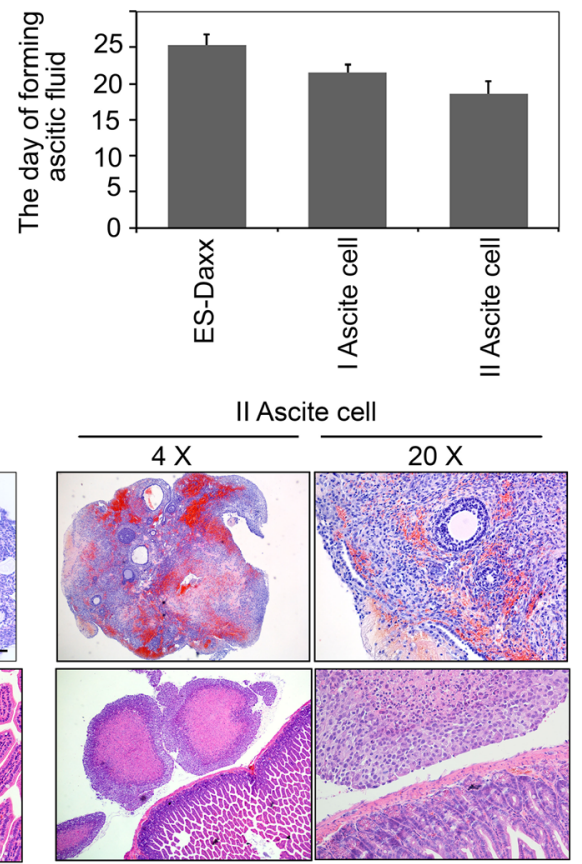

Fig. 3 DAXX promotes ascites cell metastasis in vivo. a-b Ovarian cancer cells (ES-DaxX) and I and II ascites cells ( $10^{6}$ cells for each) were implanted intraperitoneally into different nude mice. After 20 days, tumors were removed and weighed $(n=5)$. c Quantify ascites formation time (d). $\mathbf{d}$ ES-Daxx and II ascites cells were injected intraperitoneally into nude mice $\left(10^{6}\right.$ cells/mouse). HE staining showing cells metastasis to the intestine and ovary

3 weeks later. Scale bar, $250 \mu \mathrm{m}$

expression in ascites cells tumors using immunohistochemistry. As shown in Fig. 5a-b, p-ERK1/2 was highly expressed in II ascites cell tumors. However, p-AKT was found to be minimally expressed in II ascites cell tumors. In order to confirm these results, we measured p-ERK1/2 expression in ascites cells using a western blot. We found that $\mathrm{p}$-ERK $1 / 2$ and CEBP- $\beta$ were highly expressed in a passage-dependent manner (Fig. 5c). A previous study showed that CEBP- $\beta$ directly interacts with DAXX [13]. Next, we investigated the interaction between DAXX and CEBP- $\beta$ by co-immunoprecipitation in ascites cells. As shown in Fig. 5d, DAXX was found to be co-immunoprecipitated with CEBP- $\beta$. After confirming that DAXX interacts with CEBP- $\beta$ in ovarian cancer ascites cells, we investigated the expression of CEBP- $\beta$ in human ovarian cancer tissues by immunohistochemistry (Fig. 5e). We found that CEBP- $\beta$ and DAXX were significantly expressed in human ovarian cancer tissues (Fig. 5e). To confirm the function of CEBP- $\beta$, we detect CEBP- $\beta$ target gene TFF1 and Fog2 expression in ES-2-DAXX cells, I ascites cells and II ascites cells. We found that II ascites cells decrease TFF1 and Fog2 expression (new Fig. 5f). The results showed that CEBP- $\beta$ transcriptional activity were increased in a passage-dependent manner. These results suggest that DAXX integrated with CEBP- $\beta$ and promoted ascites cells survival and migration.

\section{Discussion}

Ovarian cancer is the most lethal tumor of all human gynecological malignancies. It is estimated that 220,000 new cases of ovarian cancer and 140,000 deaths are reported every year [14]. Due to the lack of symptoms and adequate screening methods in early stages, more than $60 \%$ of patients are diagnosed with advanced stages of ovarian cancer [15]. Ovarian cancer has a specific transmission pattern that is different from other malignancies. Tumors generally diffuse in abdominal cavity; even after recurrence, it is mostly confined to the peritoneal cavity, where it can carry out immune-suppressive activity [16]. Furthermore, for effective immune therapy, identification of the tumor antigen is required; for cellular immune therapy, the epitope recognized by $\mathrm{T}$-cells must be identified. 


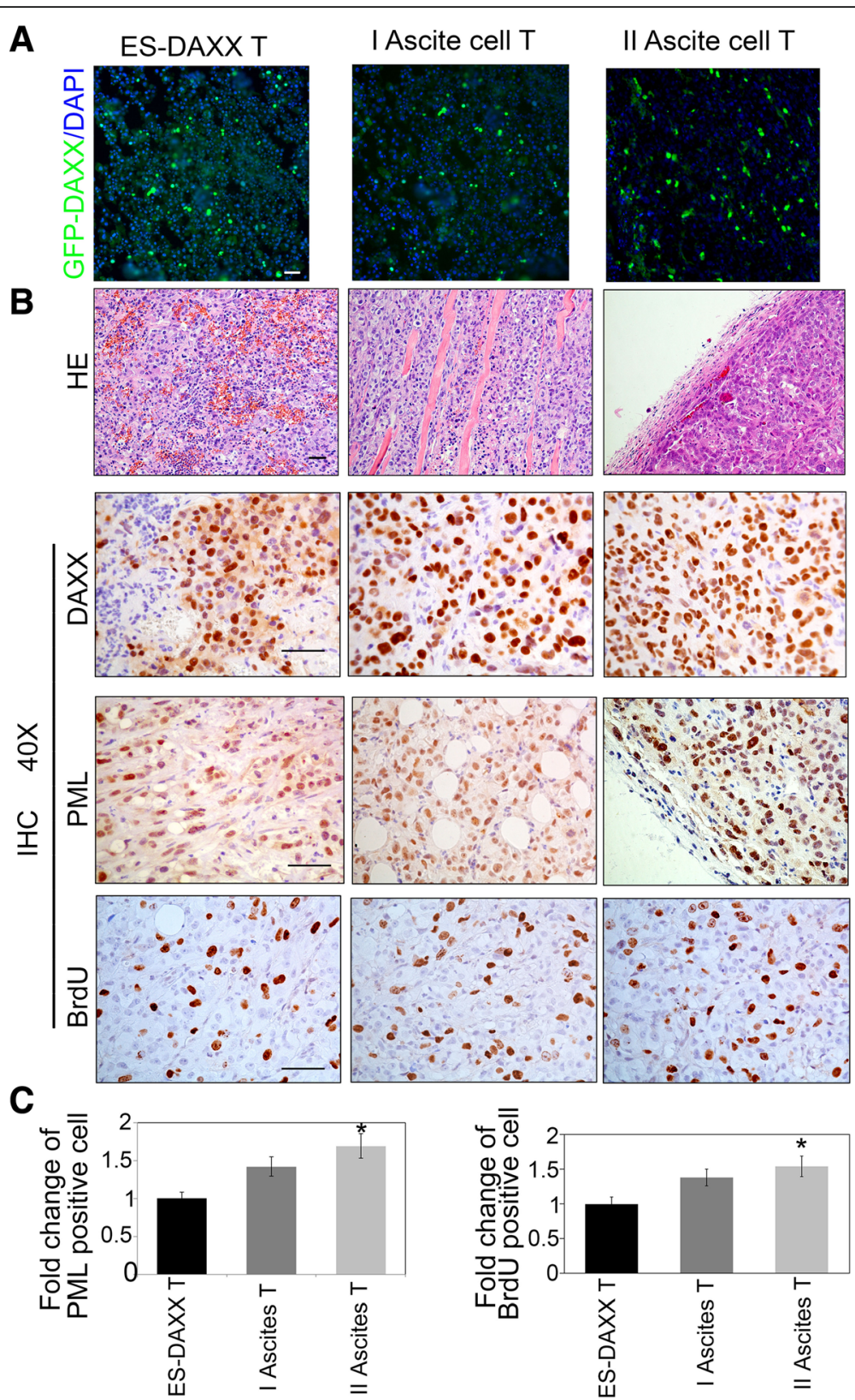

Fig. 4 DAXX promotes ascites cell proliferation in vivo. a Cryosections were prepared from tumor tissues derived from GFP-DAXX-overexpressing ascites cells. $\mathbf{b}$ HE and Immunohistochemistry staining for DAXX, PML, and BrdU in representative DAXX-overexpressingascites cells. Scale bar, $50 \mu \mathrm{m}$. $\mathbf{c}$ Quantify PML and BrdU positive cells in B. *, $p<0.05$

DAXX can be either a pro- or anti-apoptotic factor, depending on the cell type [17]. DAXX was initially identified as a cytoplasmic molecule that links Fas signaling to the c-Jun N-terminal kinase (JNK) pathway via apoptosis signal-regulating kinase 1 (ASK1) [18]. In addition to its role in the cytoplasm, DAXX acts as a transcriptional co-repressor in the nuclear compartment. DAXX has been found to be associated with multiple proteins involved in transcriptional repression, such as HDAC1, DNA methyltransferase 1 (DMNT1), and $\alpha$-thalassaemia/mental retardation syndrome X-linked (ATRX) [19-21]. DAXX also suppresses the activity of several transcription factors, including ETS1, Pax3, glucocorticoid receptor (GR), and p53 [22-25]. DAXX-dependent recruitment of H3.3 into PML-NBs both in proliferating cells, thus establishing PML-NBs as important assembly points for newly synthesized H3.3 histones and regulated gene expression. H3.3 is found enriched at active genes, centromeric heterochromatin, and telomeres, and has been proposed to 

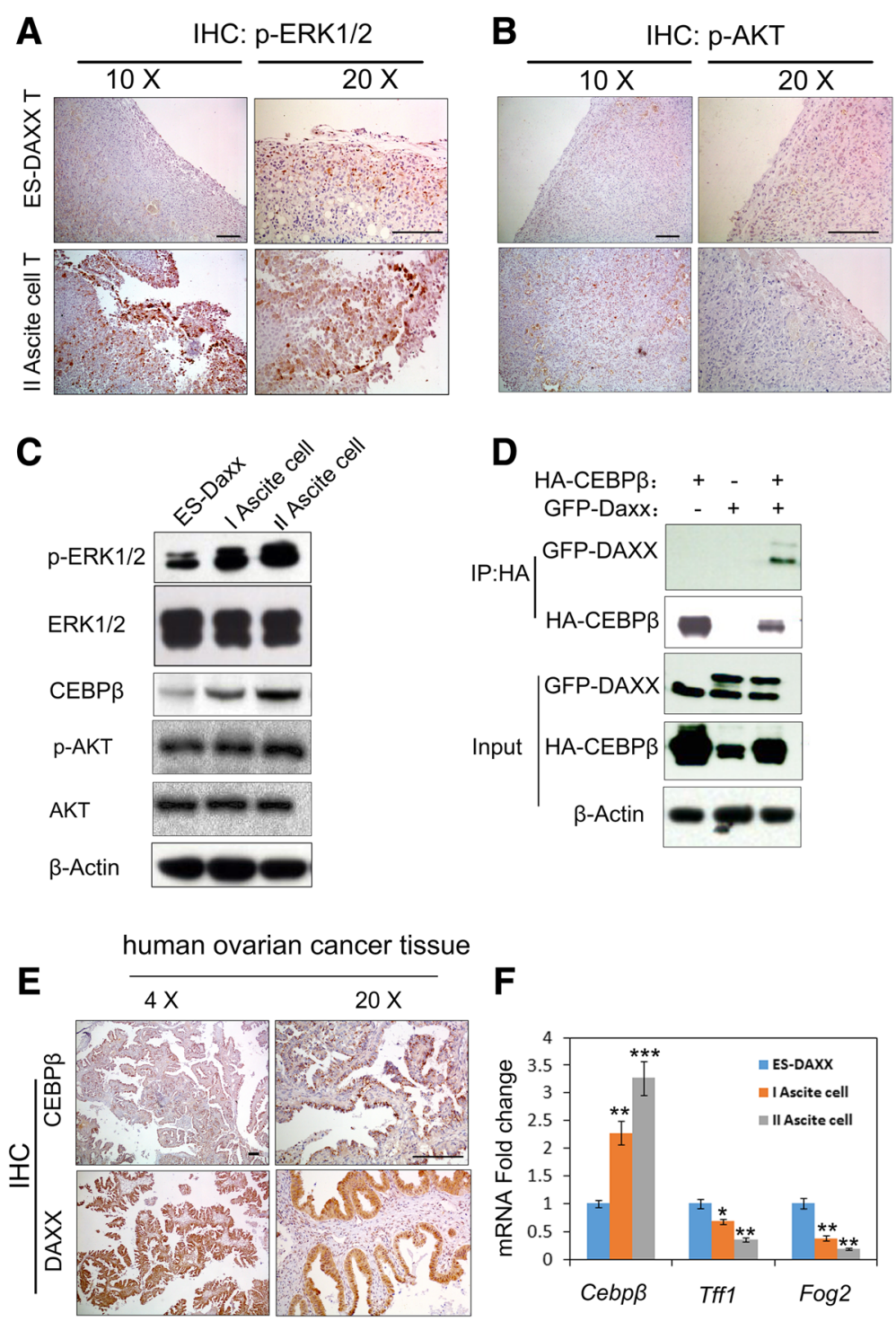

Fig. 5 DAXX binds to CEBP- $\beta$ and promotes ascites cell proliferation in vivo. a-b Immunohistochemistry staining for $p$-ERK1/2 and p-AKT in mouse tumor tissue. Scale bar, 200 mm. c DAXX-overexpressing ascites cells were subjected to immunoblotting analysis with antibodies against the indicated proteins. $\mathbf{d}$ DAXX-overexpressing ascites cells were transfected with the indicated combinations of plasmids encoding HA-CEBP- $\beta$. Cells were lysed after $24 \mathrm{~h}$, and protein extracts were immunoprecipitated with anti-HA antibodies, followed by SDS-PAGE and western blotting. e Immunohistochemical analysis of DAXX and CEBP- $\beta$ levels in human ovarian tumor tissue samples $(n=10)$. Sections were counterstained with hematoxylin and eosin. Scale bar, $200 \mu \mathrm{m}$. f Cebpß, Tff1 and p16 mRNA expressions in ES-Daxx, I and II ascites cells were determined by Q-PCR

act as important carrier of epigenetic information [26]. In our previous study, we found that DAXX was significantly expressed in human ovarian cancer tissue and weakly expressed in normal ovarian tissue. Female athymic nude mice were injected intraperitoneally with ES-2-DAXX cells or DAXX silencing cell (ES-2 shDAXX). Nude mice that injected ES-DAXX cells accumulated large amounts of ascites. These results showed that DAXX-overexpression played important role in ovarian cancer ascites forming [8]. In this study, we found that ES-2-DAXX cells promoted ascites cells proliferation and migration. DAXX co-localized with PML in ovarian cancer cells nuclei. DAXX and PML nuclear foci dramatically increase in a passage-dependent manner in ascites cells. This result showed that the co-localization of DAXX and PML maybe increased ascites cell-related gene expression by epigenetic regulation and promoted ascites forming.

It is well known that ascites-induced signaling events trigger the activation of both the ERK1/2 and AKT pathways. MAPK pathways is present in all cancer cells and regulates cell differentiation, proliferation, migration, apoptosis, and inflammation [27, 28]. In mammals, the activation of the MAPK/ERK pathway requires Ras, a 
single $\mathrm{G}$ protein recruited by receptor and non-receptor tyrosine kinases [29]. Activation of the ERK1/2 pathway is also involved in tumor cell survival by coupling survival stimuli to transcription factors controlling gene expression. For example, higher levels of phospho-ERK1/2 in ovarian cancer cells were found to be associated with an increased resistance to cisplatin [30]. Our results also showed that DAXX induced ovarian cancer ascites cell proliferation through ERK activation. These results were consistent with a previous study [31].

Phosphatidylinositol-4,5-bisphosphate 3 kinase (PI3K)/ AKT may be a key pathway in the regulation of cell survival under anchorage-independent stress [32]. Previous studies demonstrating AKT activation by ascites cells prompted us to investigate whether AKT was also involved in DAXX-overexpression-induced ascites. We measured the phosphorylation of AKT in tumor tissues by immunohistochemistry, and found that AKT was not activated in DAXX-overexpression-induced ascites cells. These results indicated that ERK1/2, but not AKT, plays a major role in DAXX-overexpression-induced ascites cell proliferation.

CEBP- $\beta$ is involved in tissue-specific gene expression and participates in fundamental cellular processes such as proliferation and differentiation [33]. In addition, CEBP- $\beta$ is capable of increasing the expression of several target genes including genes coding for cytokines such as IL-6, IL-4, IL-5 and TNF $\alpha$ and genes coding for drug resistance such as $A B C C 2$ and $A B C B 1$ [34, 35]. Our results clearly demonstrated that DAXX interacts with CEBP- $\beta$ in ascites cells. This indicated that DAXXCEBP- $\beta$ promotes ascites cells growth by stimulating ascites formation, altering the components of the ascites or having any other chemokines inside the ascites that leads to such cell growth promotion. A further delineation of the mechanistic link between DAXX and CEBP- $\beta$ should allow a better understanding of DAXX functions in ovarian cancer ascites cells.

\section{Conclusions}

DAXX can induce ovarian cancer ascites formation by activating the ERK signal pathway and binding to CEBP- $\beta$.

\section{Abbreviations}

ASK1: Apoptosis signal-regulating kinase 1; ATRX: a-thalassaemia/mental retardation syndrome $X$-linked; CEBP- $\beta$ : CCAAT/enhancer-binding protein$\beta$; DAXX: Death-domain-associated protein; DMEM: Dulbecco's Modified Eagle's Medium; DNMT1: DNA methyltransferase 1; ERK: Extracellular signalrelated kinase; GR: Glucocorticoid receptor; HDAC1: Histone deacetylase 1; MAPK: Mitogen-activated protein kinase; mOSE: Mouse ovarian surface epithelium; PML: Promyelocytic leukemia protein

\section{Acknowledgements}

We thank Dr. Heng-Yu Fan of Zhejiang University for the plasmid of pLEGFPDaxx which encodethe full-length Daxx sequence and HA-CEBP- $\beta$.

This work was supported by The Natural Science Foundation of Zhejiang Province (LY17H160060, LQ13H160020). National Natural Science Foundation of China (81402162).

\section{Funding}

The Natural Science Foundation of Zhejiang Province (LY17H160060, LQ13H160020). National Natural Science Foundation of China (81402162).

\section{Availability of data and materials}

The datasets supporting the conclusions of this article are included within the article.

\section{Authors' contributions}

PW-W made substantial contributions to the study conception and conceived of the study, performed experiments, interpreted data and corrected the manuscript. LS-B designed the study and wrote the manuscript, corrected the manuscript and critically revised the manuscript. LX-P analyzed the characteristics of the images and interpreted morphological data. XY and SZ-F performed experiments and wrote specific sections of the manuscript. LS-B and PW-W designed the study and participated in the revision of the manuscript. All the authors read and approved the final manuscript.

\section{Authors' information}

Where the work was performed: Laboratory of molecular biology, college of medicine, Jiaxing University.

\section{Ethics approval}

Normal ovaries were provided by the the Jiaxing Maternity and Child Health Care Hospital, China. The use of archived samples in this study was approved by the Jiaxing University Institutional Review Board. The NIH Guides for the Care and Use of Laboratory Animals were used as all animal protocols.

\section{Consent for publication}

Not applicable.

\section{Competing interests}

The authors declare that they have no competing interests.

\section{Publisher's Note}

Springer Nature remains neutral with regard to jurisdictional claims in published maps and institutional affiliations.

Received: 27 June 2018 Accepted: 3 October 2018

Published online: 18 October 2018

\section{References}

1. Ozols RF, Bookman MA, Connolly DC, Daly MB, Godwin AK, Schilder RJ, $\mathrm{Xu} X$, Hamilton TC. Focus on epithelial ovarian cancer. Cancer Cell. 2004:5:19-24.

2. Bast RC Jr, Hennessy B, Mills GB. The biology of ovarian cancer: new opportunities for translation. Nat Rev Cancer. 2009:9:415-28.

3. Lane D, Robert V, Grondin R, Rancourt C, Piché A. Malignant ascites protect against TRAIL-induced apoptosis by activating the PI3K/Akt pathway in human ovarian carcinoma cells. Int J Cancer. 2007;121:1227-37.

4. Lane D, Goncharenko-Khaider N, Rancourt C, Piché A. Ovarian cancer ascites protects from TRAlL-induced cell death through av $\beta 5$ integrin-mediated focal adhesion kinase and Akt activation. Oncogene. 2010;29:3519-31.

5. Ahmed N, Riley C, Oliva K, Rice G, Quinn M. Ascites induces modulation of $6 \beta 1$ integrin and urokinase plasminogen activator receptor expression and associated functions in ovarian carcinoma. $\mathrm{Br}$ J Cancer. 2005;92:1475-85.

6. Giuntoli RL, Webb TJ, Zoso A, Rogers O, Diaz-Montes TP, Bristow RE, Oelke M. Ovarian cancer-associated ascites demonstrates altered immune environment: implications for antitumor immunity. Anticancer Res. 2009;29: 2875-84.

7. Yigit R, Figdor CG, Zusterzeel PL, Pots JM, Torensma R, Massuger LF. Cytokine analysis as a tool to understand tumour-host interaction in ovarian cancer. Eur J Cancer. 2011;47:1883-9.

8. Pan WW, Zhou JJ, Liu XM, Xu Y, Guo LJ, Yu C, Shi QH, Fan HY. Death domain-associated protein DAXX promotes ovarian cancer development and chemoresistance. J Biol Chem. 2013;288:13620-30.

9. Dolznig H, Rupp C, Puri C, et al. Modeling Colon Adenocarcinomas in Vitro: A 3D Co-Culture System Induces Cancer-Relevant Pathways upon Tumor Cell and Stromal Fibroblast Interaction. Am J Pathol. 2011;179:487-501. 
10. Fischbach $\mathrm{C}$, Kong HJ, Hsiong SX, et al. Cancer cell angiogenic capability is regulated by $3 \mathrm{D}$ culture and integrin engagement. Proc Natl Acad Sci U S A. 2009;106:399-404.

11. Pickl M, Ries $\mathrm{CH}$. Comparison of $3 \mathrm{D}$ and $2 \mathrm{D}$ tumor models reveals enhanced HER2 activation in 3D associated with an increased response to trastuzumab. Oncogene. 2009;28:461-8.

12. Pan WW, Yi FP, Cao LX, Liu XM, Shen Z, Bu Y, Xu Y, Fan HY, Song FZ. DAXX silencing suppresses mouse ovarian surface epithelial cell growth by inducing senescence and DNA damage. Gene. 2013;526:287-94.

13. Wethkamp N, Klempnauer KH. Daxx is a transcriptional repressor of CCAAT/ enhancer-binding protein $\beta$. J Biol Chem. 2009;284:28783-94.

14. Innao P, Pothisuwan $M$, Pengsa $P$. Does human epididymis protein 4 (HE4) have a role in prediction of recurrent epithelial ovariancancer. Asian Pac J Cancer Prev. 2016;17:4483-6.

15. Jelovac D, Armstrong DK. Recent progress in the diagnosis and treatment of ovarian cancer. CA Cancer J Clin. 2011;61(3):183-203.

16. Auer K, Bachmayr-Heyda A, Sukhbaatar N, Aust S, Schmetterer KG, Meier SM, Gerner C, Grimm C, Horvat R, Pils D. Role of the immune system in the peritoneal tumor spread of high grade serous ovarian cancer. Oncotarget. 2016;7:61336-54.

17. Chen LY, Chen JD. DAXX silencing sensitizes cells to multiple apoptotic pathways. Mol Cell Biol. 2003;23:7108-21.

18. Yang X, Khosravi-Far R, Chang HY, Baltimore D. DAXX, a novel Fas-binding protein that activates JNK and apoptosis. Cell. 1997;89:1067-76.

19. Li H, Leo C, Zhu J, Wu X, O'Neil J, Park EJ, Chen JD. Sequestration and inhibition of DAXX-mediated transcriptional repression by PML. Mol Cell Biol. 2000;20:1784-96.

20. Muromoto R, Sugiyama K, Takachi A, Imoto S, Sato N, Yamamoto T, Oritani K, Shimoda K, Matsuda T. Physical and functional interactions between DAXX and DNA methyltransferase 1-associated protein, DMAP1. J Immunol. 2004;172:2985-93.

21. Ishov AM, Vladimirova OV, Maul GG. Heterochromatin and ND10 are cellcycle regulated and phosphorylation-dependent alternatenuclear sites of the transcription repressor DAXX and SWI/SNF protein ATRX. J Cell Sci. 2004;117:3807-20.

22. Li R, Pei H, Watson DK, Papas TS. EAP1/DAXX interacts with ETS1 and represses transcriptional activation of ETS1 target genes. Oncogene. 2000;19:745-53.

23. Lehembre F, Müller S, Pandolfi PP, Dejean A. Regulation of Pax3 transcriptional activity by SUMO-1-modifiedPML. Oncogene. 2001;20:1-9.

24. Lin DY, Lai MZ, Ann DK, Shih HM. Promyelocytic leukemia protein (PML) functions as a glucocorticoid receptor co-activator by sequestering DAXX to the PML oncogenic domains (PODs) to enhance its transactivation potential. J Biol Chem. 2003;278:15958-65.

25. Zhao LY, Liu J, Sidhu GS, Niu Y, Liu Y, Wang R, Liao D. Negative regulation of p53 functions by DAXX and theinvolvement of MDM2. J Biol Chem. 2004;279:50566-79.

26. Salomoni P. The PML-Interacting Protein DAXX: Histone Loading Gets into the Picture. Front Oncol. 2013;3:152.

27. Yu P, Ye L, Wang H, Du G, Zhang J, Zhang J, Tian J. NSK-01105 inhibits proliferation and induces apoptosis of prostate cancer cells by blocking the Raf/MEK/ERK and PI3K/Akt/mTOR signal pathways. Tumour Biol. 2015;36: 2143-53.

28. Jiang M, Wen F, Cao J, Li P, She J, Chu Z. Genome-wide exploration of the molecularevolution and regulatory network of mitogen-activatedprotein kinase cascades uponmultiple stresses in Brachypodium distachyon. BMC Genomics. 2015;16:228.

29. Knight T, Irving JA. Ras/Raf/MEK/ERK pathway activation in childhood acute lymphoblastic leukemia and its therapeutic targeting. Front Oncol. 2014;4:160

30. Lee $\mathrm{S}$, Yoon S, Kim DH. A high nuclear basal level of ERK2 phosphorylation contributes to the resistance of cisplatin-resistant human ovarian cancer cells. Gynecol Oncol. 2007;104:338-44.

31. Goncharenko-Khaider N, Matte I, Lane D, Rancourt C, Piche A. Ovarian cancer ascites increase Mcl-1 expression in tumor cells through ERK1/2-Elk-1 signaling to attenuate TRAIL-induced apoptosis. Mol Cancer. 2012;11:84.

32. Correa RJ, Peart T, Valdes YR, DiMattia GE, Shepherd TG. Modulation of AKT activity is associated with reversibledormancy in ascites-derived epithelial ovarian cancer spheroids. Carcinogenesis. 2011;33:49-58.

33. Zhu S, Yoon K, Sterneck E, Johnson PF, Smart RC. CCAAT/enhancer binding protein- $\beta$ is a mediator of keratinocyte survival and skin tumorigenesis involving oncogenic Ras signaling. Proc Natl Acad Sci U S A. 2002;99:207-12.
34. Lee HG, Minematsu $H$, Kim KO, Celil Aydemir AB, Shin MJ, Nizami SA, Chung $\mathrm{KJ}$, Hsu AC, Jacobs CR, Lee FY. Actin and ERK1/2-CEBP $\beta$ signaling mediates phagocytosis-induced innate immune response of osteoprogenitor cells. Biomaterials. 2011;32:9197-206.

35. Mäuser W, Perwitz N, Meier B, Fasshauer M, Klein J. Direct adipotropic actions of atorvastatin: differentiation state-dependent induction of apoptosis, modulation of endocrine function, and inhibition of glucose uptake. Eur J Pharmacol. 2007;564:37-46.
Ready to submit your research? Choose BMC and benefit from:

- fast, convenient online submission

- thorough peer review by experienced researchers in your field

- rapid publication on acceptance

- support for research data, including large and complex data types

- gold Open Access which fosters wider collaboration and increased citations

- maximum visibility for your research: over $100 \mathrm{M}$ website views per year

At BMC, research is always in progress.

Learn more biomedcentral.com/submissions 